\title{
Epidemiology, anticoagulant treatment and risk of thromboembolism in patients with valvular atrial fibrillation: Results from Atrial Fibrillation in Turkey: Epidemiologic Registry (AFTER)
}

\author{
Hasan Kaya ${ }^{1}$, Faruk Ertaş ${ }^{1}$, Zekeriya Kaya ${ }^{2}$, Nihan Kahya Eren ${ }^{3}$, Murat Yüksel ${ }^{1}$, \\ Bayram Köroğlu ${ }^{4}$, Nuri Köse ${ }^{5}$, Abdulkadir Yıldız ${ }^{1}$, Tolga Çimen ${ }^{6}$, \\ Mehmet Siddık Ülgen ${ }^{1}$; for the AFTER Investigators \\ ${ }^{1}$ Department of Cardiology, Dicle University Faculty of Medicine, Diyarbakır, Turkey \\ ${ }^{2}$ Department of Cardiology, Harran University Faculty of Medicine, Şanlıurfa, Turkey \\ ${ }^{3}$ Department of Cardiology, Atatürk Education and Research Hospital, İzmir, Turkey \\ ${ }^{4}$ Department of Cardiology, Siyami Ersek Education and Research Hospital, İstanbul, Turkey \\ ${ }^{5}$ Department of Cardiology, Yücelen Hospital, Muğla, Turkey \\ ${ }^{6}$ Department of Cardiology, Dışkapı Education and Research Hospital, \\ Yıldırım Beyazıt University, Ankara, Turkey
}

\begin{abstract}
Background: The aim of this study was to perform a multicenter, prospective investigation regarding the epidemiology, the current effectiveness of therapeutic anticoagulation, and the risk of thromboembolism in patients with valvular atrial fibrillation $(A F)$ based on the records of the Atrial Fibrillation in Turkey: Epidemiologic Registry (AFTER) study.

Methods: Patients were selected from a total of 2,242 consecutive admissions that presented with $A F$ diagnosed via electrocardiogram. Those diagnosed with non-valvular $A F$ were excluded from the AFTER study population, which left 497 patients with valvular AF for analysis.

Results: The etiology of valvular AF in patients was either attributed to rheumatic mitral valve stenosis $(n=217)$ or possessing a prosthetic heart valve $(n=280)$. Out of all the patients with valvular $A F, 83.1 \%$ were taking warfarin for anticoagulation. Only $36.1 \%$ demonstrated a therapeutic international normalized ratio (INR), and among those patients it was found that $19.1 \%$ exhibited a labile INR. Multivariate analysis revealed that age was the only independent predictor of thromboembolic events in patients with valvular AF.

Conclusions: Many valvular AF patients are not maintained at therapeutic INR levels, which poses a threat to patient health as they age and are at greater risk for thromboembolism. (Cardiol J 2014; 21, 2: 158-162)
\end{abstract}

Key words: atrial fibrillation, valvular, predictor, anticoagulant treatment

\section{Introduction}

The prevalence of atrial fibrillation $(\mathrm{AF})$ and AF-related adverse events is growing worldwide along with the rise in the elderly population. In fact $\mathrm{AF}$ is the most common arrhythmia seen in our practice [1]. Clinically we subdivide AF into 2 main categories including valvular and non-valvular AF,

Address for correspondence: Hasan Kaya, MD, Dicle University Faculty of Medicine, Department of Cardiology, Diyarbakır, Turkey, tel: 0412 2488001, fax: 0412 2488523, e-mail: dr_hasankaya@yahoo.com 
which are associated with a 17 and 5 fold increased risk of stroke per annum, respectively [1, 2]. Thromboembolism is the leading cause of AF-related adverse events, but it is valvular $\mathrm{AF}$ that is associated with the highest risk of stroke. Even so, most studies investigating $\mathrm{AF}$ and stroke have been mostly performed with non-valvular AF patients. This has led to a paucity of detailed epidemiological information regarding risk factors for thromboembolism in patients with valvular AF [3-10]. Although there was a multicenter study that investigated the epidemiology of heart valve diseases in Turkey, this study did not focus on valvular AF patients [11]. To our knowledge the Atrial Fibrillation in Turkey: Epidemiologic Registry (AFTER) multicenter cohort study was the first that strived to close the gap in knowledge pertaining to the demographic characteristics, attainment of therapeutic international normalized ratio (INR), and risk of thromboembolism in patients with valvular AF.

\section{Methods}

\section{Study design and patient selection}

AFTER is a prospective, multicenter cohort study that was designed with the aim to describe the epidemiology of AF in Turkey [12]. A total of 2,242 patients were recruited from 17 hospitals so to have representation from the populations characteristic of the 7 geographical regions of Turkey. This recruitment period took place during the period from April 2012 to December 2012 for a total duration of about 9 months.

The inclusion criteria were the following: "all consecutive patients over 18 years of age who presented to cardiology outpatient clinics with at least one attack of $\mathrm{AF}$ identified on electrocardiographic examination". Patients that refused to participate in the study or sign the consent form were excluded. A licensed cardiologist obtained, recorded and evaluated patient basic demographic data and medications. Every patient was required to sign an informed consent document and complete a standard registration form. The AFTER study was approved by the Ethics Committee.

\section{Descriptions}

Types of AF were defined according to the European Society of Cardiology (ESC) guidelines [1]. Valvular AF was defined as a patient presenting with $\mathrm{AF}$ and rheumatic mitral valve stenosis or prosthetic heart valve(s) [1, 2]. Paroxysmal AF was defined as self-terminating and usually lasting from $48 \mathrm{~h}$ to 7 days. Persistent AF was considered an episode of AF that either lasts longer than 7 days or requires termination by cardioversion. Permanent $\mathrm{AF}$ was described as $\mathrm{AF}$ that occurs on 2 occasions within at least 6 months separating each episode with no evidence of sinus rhythm in between.

All patients received routine electrocardiographic and echocardiographic examination. Hypertension was defined as a blood pressure measurement greater than $140 / 90 \mathrm{~mm} \mathrm{Hg}$, a prior diagnosis of hypertension or requiring antihypertensive medication. Diabetes mellitus was designated as a fasting blood glucose level greater than $126 \mathrm{mg}$, a prior diagnosis of diabetes or being on anti-diabetic therapy. Vascular disease was described as having a previous myocardial infarction, a complex aortic plaque or peripheral artery disease.

Therapeutic INR range was defined as 2.0-3.0 in patients with rheumatic mitral valve stenosis and aortic prosthetic valves. For patients with prosthetic mitral valves or both aortic and mitral prosthetic valves, the therapeutic INR range was 2.5-3.5 [13]. Labile INR was considered attaining therapeutic range less than $60 \%$ of the time [14].

\section{Statistical analysis}

Statistical Package for Social Sciences software (SPSS 12, Chicago, IL, USA) was used for data analysis. Normality analyses were assessed using Kolmogorov-Smirnov and Shapiro-Wilk tests. Descriptive parameters were shown as the mean \pm one standard deviation or in percentages. For quantitative data comparison, normally distributed parameters were compared using Student's t-test. Parameters that did not follow a normal distribution were compared using the Mann-Whitney U test. The $\chi^{2}$ test was used for the comparison of qualitative data. A multivariate logistic regression analysis was performed to evaluate the independent predictors of thromboembolic events using age, gender, hypertension, heart failure, vascular disease and diabetes mellitus as potential covariates. A p-value lower than 0.05 was considered significant.

\section{Results}

The entire patient cohort with AF numbered to 2,242 , and after removing patients with non-valvular AF the final cohort consisted of 497 patients with valvular AF. There were 217 patients with rheumatic mitral valve stenosis and 280 patients had prosthetic heart valves. Among patients with prosthetic valves, $207(73.9 \%)$ of them had mitral valve replacement (MVR), $49(17.5 \%)$ had aortic valve replacement (AVR) and $24(8.6 \%)$ had both MVR and AVR. Valvular AF patient demographics are detailed in Table 1 . The mean age of these pa- 
Table 1. Baseline patient demographics.

\begin{tabular}{lc} 
Mean age [years] & $58.4 \pm 11.5$ \\
Gender: & \\
Male & $139(28 \%)$ \\
Female & $358(72 \%)$ \\
Age $\geq 75$ years & $37(7.4 \%)$ \\
Body mass index $\left[\mathrm{kg} / \mathrm{m}^{2}\right]$ & $27.0 \pm 4.7$ \\
Atrial fibrillation type: & \\
$\quad$ Mitral stenosis & $217(43.7 \%)$ \\
Prosthetic valve & $280(56.3 \%)$ \\
Paroxysmal & $39(7.8 \%)$ \\
Persistent-permanent & $458(92.2 \%)$ \\
Hypertension & $227(45.7 \%)$ \\
Heart failure/LV dysfunction & $104(20.9 \%)$ \\
Type II diabetes mellitus & $76(15.3 \%)$ \\
Vascular disease & $44(8.9 \%)$ \\
Thyroid dysfunction & $18(3.6 \%)$ \\
Smoking & $60(12.1 \%)$ \\
Stroke/TIA/thromboembolism & $76(15.3 \%)$ \\
History of stroke & $66(13.3 \%)$ \\
Bleeding history & $79(15.9 \%)$ \\
Anticoagulant use & $413(83.1 \%)$ \\
Effective INR (n = 413) & $149(36.1 \%)$ \\
Labile INR ( $=413)$ & $79(19.1 \%)$ \\
\hline
\end{tabular}

Continuous data are expressed as mean \pm standard deviation; categorical data are expressed as $\mathrm{n}(\%)$; INR - international normalized ratio; LV - left ventricle; TIA — transient ischemic attack tients was $58.4 \pm 11.5$ years. Among all valvular $\mathrm{AF}$ patients, $92.2 \%$ demonstrated permanent-persistent $\mathrm{AF} .72 \%$ of the $\mathrm{AF}$ patients were female. Hypertension was the most common comorbid condition of $46 \%$. Other frequent comorbidities included heart failure, diabetes mellitus and vascular disease with frequencies of $21 \%, 15 \%$ and $9 \%$, respectively. $15 \%$ of patients had a history of stroke, transient ischemic attack or systemic thromboembolism. Conversely, $15.9 \%$ of patients had a history of bleeding.

About $83 \%$ of the patients were taking the oral anticoagulant medication warfarin and $36.1 \%$ of them maintained therapeutic INR levels. However, $19.1 \%$ of the patients that were on warfarin therapy demonstrated labile INR.

When comparisons were made between patients with mitral stenosis vs. those who had prosthetic valves, heart failure was more common in patients with prosthetic valves (Table 2). Rates of stroke and bleeding were similar in both these groups. The rate of warfarin use in patients with prosthetic valves was higher than in patients with rheumatic valvular stenosis $(95.4 \%$ vs. $67.3 \%$, $\mathrm{p}<0.001)$. Patients with MVR demonstrated the lowest rates of therapeutic INR achievement at $29 \%$ as their INRs were suboptimal, ranging 2.00-2.49. A comparison between warfarin use and

Table 2. Demographic characteristics of patients with mitral valve stenosis and prosthetic valves.

\begin{tabular}{|c|c|c|c|}
\hline Variables & Mitral stenosis $(n=217)$ & Prosthetic valve $(n=280)$ & $\mathbf{P}^{*}$ \\
\hline Mean age [years] & $59.1 \pm 11.9$ & $57.9 \pm 11.2$ & 0.247 \\
\hline Female & $160(73.7 \%)$ & $198(70.7 \%)$ & 0.457 \\
\hline Body mass index $\left[\mathrm{kg} / \mathrm{m}^{2}\right]$ & $27.2 \pm 4.9$ & $26.9 \pm 4.6$ & 0.403 \\
\hline Atrial fibrillation type: & & & 0.002 \\
\hline Paroxysmal & $26(12 \%)$ & $13(5 \%)$ & \\
\hline Persistent & $41(19 \%)$ & $39(14 \%)$ & \\
\hline Permanent & $150(69 \%)$ & $228(81 \%)$ & \\
\hline Hypertension & $102(47 \%)$ & $125(45 \%)$ & 0.600 \\
\hline Heart failure/LV dysfunction & $34(16 \%)$ & $70(25 \%)$ & 0.011 \\
\hline Diabetes mellitus & $34(16 \%)$ & $42(15 \%)$ & 0.837 \\
\hline Vascular disease & $21(10 \%)$ & $23(8 \%)$ & 0.569 \\
\hline Stroke/TIA/thromboembolism & $35(16 \%)$ & $41(15 \%)$ & 0.648 \\
\hline History of stroke & $32(15 \%)$ & $34(12 \%)$ & 0.396 \\
\hline Bleeding history & $30(14 \%)$ & $49(18 \%)$ & 0.266 \\
\hline Anticoagulant use & $146(67.3 \%)$ & $267(95.4 \%)$ & $<0.001$ \\
\hline Effective INR ( $n=413$ ) & $57(39 \%)$ & $92(35 \%)$ & 0.354 \\
\hline Labile INR ( $n=413$ ) & $25(17 \%)$ & $54(20 \%)$ & 0.444 \\
\hline Ejection fraction [\%] & $58.3 \pm 8.7$ & $51.2 \pm 12.8$ & $<0.001$ \\
\hline LA diameter [cm] & $5.1 \pm 0.9$ & $5.2 \pm 0.9$ & 0.461 \\
\hline SEC-thrombus & $31(14 \%)$ & $12(4 \%)$ & $<0.001$ \\
\hline
\end{tabular}

Continuous data are expressed as mean \pm standard deviation; categorical data are expressed as n (\%); *Student's t-test, Mann-Whitney $\mathrm{U}$ test and $\chi^{2}$ test; INR - international normalized ratio; LV — left ventricle; LA — left atrium; SEC — spontaneous echo contrast; TIA - transient ischemic attack 


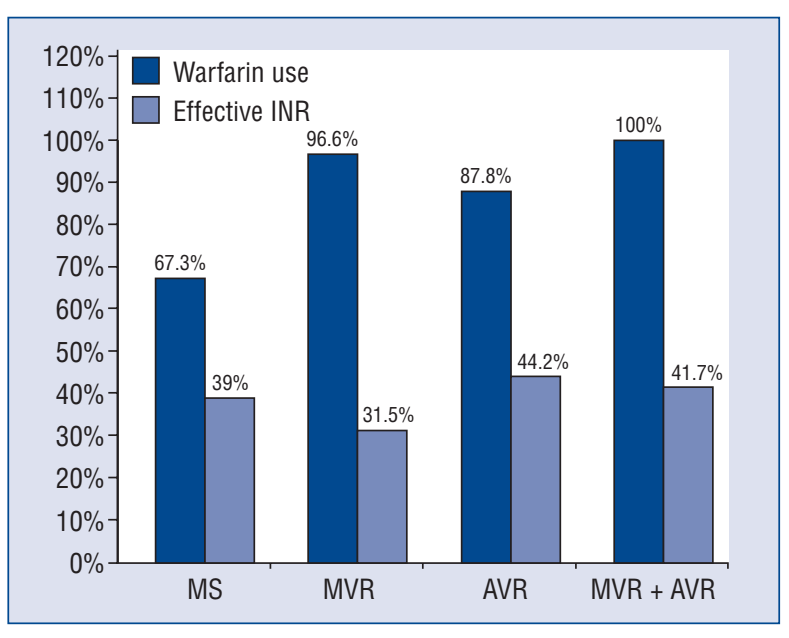

Figure 1. Comparison of oral anticoagulant use and therapeutic international normalized ratio (INR) achievement in patients with mitral stenosis (MS) and prosthetic valves; AVR — aortic valve replacement; MVR mitral valve replacement.

achievement of therapeutic INR in patients with mitral valve stenosis vs. patients with prosthetic valves is in Figure 1.

Echocardiographic examinations showed that a lower ejection fraction was more common in patients with prosthetic valves. However, spontaneous echo contrast or thrombus visualization in the left atrium was more commonly observed in patients with rheumatic mitral valve stenosis. The average left atrial diameters were similar between both study groups.

Multivariate analysis demonstrated that age was the only independent predictor of thromboembolic events (odds ratio 1.034, 95\% confidence interval 1.009-1.059, $\mathrm{p}=0.007)$. Specifically, each year of aging was associated with a $3.4 \%$ increase in thromboembolic event risk (Table 3).

Table 3. Logistic regression of the independent predictors of stroke/transient ischemic attack/ /thromboembolic events.

\begin{tabular}{lccc}
\hline Variable & $\begin{array}{c}\text { Odds } \\
\text { ratio }\end{array}$ & $95 \% \mathrm{Cl}$ & $\mathbf{P}^{*}$ \\
\hline Age & 1.034 & $1.009-1.059$ & 0.007 \\
Gender & 1.212 & $0.696-2.113$ & 0.497 \\
Hypertension & 1.630 & $0.960-2.769$ & 0.070 \\
Heart failure & 0.935 & $0.505-1.732$ & 0.830 \\
Vascular disease & 0.794 & $0.337-1.873$ & 0.598 \\
Diabetes mellitus & 0.960 & $0.484-1.907$ & 0.908 \\
\hline
\end{tabular}

*Multivariate logistic regression analysis; $\mathrm{Cl}$ - confidence interval

\section{Discussion}

Research in AF has been mostly conducted in Western countries, and almost all of these studies only involved non-valvular AF patients. Several countries that have measured the incidence of valvular AF include the United States at 6\%, Japan at $14 \%$ and the AFNET study demonstrated a $9 \%$ incidence in Germany $[5,7,15]$. In a previous study performed in Turkey it was found that valvular AF has a frequency of $22 \%$, which likely reflects the higher rates of rheumatic heart disease in Turkey as compared to other developed nations [3]. In a different Turkish multicenter study performed with 1,300 patients it was determined that $11 \%$ had mitral valve stenosis and $13 \%$ had prosthetic valves [11]. Furthermore, AF was detected in $28 \%$ of patients with valvular disease, and of patients with both $\mathrm{AF}$ and valvular disease $38 \%$ had mitral stenosis. By investigating valvular AF in Turkey, we hope to inform the international community about its etiology, prevalence, treatment, and the risk factors associated with thromboembolism.

According to our findings, one-fifth of AF cases were valvular in origin. Rheumatic valvular disease made up a slight majority of these cases at 56\% while prosthetic valves made up the difference at $44 \%$. Of note, MVR were the most common prosthetic heart valves. In fact, valvular AF occurred more frequently in females, which may be a reflection of the greater likelihood of women having mitral stenosis as compared to men. Additionally, most patients exhibited permanent $\mathrm{AF}$, and the most common comorbid condition was hypertension in valvular $\mathrm{AF}$ patients.

However, one of the most compelling findings in our study was poor INR achievement among valvular AF patients. Upon analyzing the entire cohort in terms of warfarin use, $83.1 \%$ of patients were taking this anticoagulant. Nevertheless, only $36.1 \%$ of those patients demonstrated a therapeutic INR level. Unfortunately, it was not possible to compare our data with other studies, because our literature search yielded no papers regarding warfarin use and the attainment of effective INR for patients with valvular AF.

Subgroup analysis revealed that the highest rate of warfarin use was detected in patients with both MVR and AVR. Conversely, patients with rheumatic mitral valve stenosis had the lowest rate of warfarin use. To distinguish between therapeutic and suboptimal INRs we adopted the American College of Chest Physicians (ACCP) recommendations, because they define INR limits based on 
heart valvular disease type [13]. Interestingly, the group with the lowest rate of therapeutic INR achievement was comprised of patients with MVR alone. According to the ACCP, therapeutic INR for patients with MVR ranges 2.50-3.50, yet $29 \%$ of these patients had suboptimal INRs ranging 2.00-2.49 . There are other guidelines that use more sophisticated criteria to determine therapeutic INR such as the ESC guidelines that subdivides target INR levels according to the prosthetic valve's thrombogenicity and clinical risk factors [16]. Yet, in our clinical practice our patients are usually not aware of the prosthetic valve type that they have, which poses a great barrier in determining the appropriate INR.

Because patients with valvular AF may be at risk of thromboembolic events due to having sub-therapeutic INRs, we strived to find a means to lower the risk of stroke in these patients. There are 2 standardized measures to identify stroke risk in non-valvular AF that include the CHADSVASC and CHADS scores, but no such score exists for valvular AF $[17,18]$. Thus we performed a regression analysis using CHADSVASC score parameters. Only age was detected as an independent predictor of thromboembolic events in patients with valvular AF. Specifically, with every year of aging there is a $3.4 \%$ increased risk of thromboembolism in these patients.

\section{Limitations of the study}

INR values were not measured at a central laboratory. The analysis was based on a cross-sectional survey and the prospective data will be gathered in the future.

\section{Conclusions}

According to the AFTER study, approximately $20 \%$ of AF cases in Turkey were of valvular origin. Even though $83.1 \%$ of these patients were using warfarin, only one-third of them achieved a therapeutic INR level. Age was the only independent predictor of stroke in this patient group. These results suggest that the clinical management for anticoagulation in these patients is currently sub-optimal. Also more research must be done to determine what risk factors predispose valvular $\mathrm{AF}$ patients to stroke. This way, practice guidelines specifically tailored to patients with valvular $\mathrm{AF}$ may be formulated so that improvements can be made in their clinical management.

Conflict of interest: none declared

\section{References}

1. European Heart Rhythm Association; European Association for Cardio-Thoracic Surgery, Camm AJ, Kirchhof P, Lip GY et al. Guidelines for the management of atrial fibrillation: the Task Force for the Management of Atrial Fibrillation of the European Society of Cardiology (ESC). Eur Heart J, 2010; 31: 2369-2429.

2. Fuster V, Rydén LE, Cannom DS et al; American College of Cardiology Foundation/American Heart Association Task Force. 2011 ACCF/AHA/HRS focused updates incorporated into the ACC/AHA/ESC 2006 guidelines for the management of patients with atrial fibrillation: a report of the American College of Cardiology Foundation/American Heart Association Task Force on practice guidelines. Circulation, 2011; 123: e269-367.

3. Ertaş F, Kaya H, Kaya $Z$ et al. Epidemiology of Atrial Fibrillation in Turkey: Preliminary Results of the Multicenter AFTER (Atrial Fibrillation in Turkey: Epidemiologic Registry) Study. Turk Kardiyol Dern Ars, 2013; 41: 99-104.

4. Ertas F, Eren NK, Kaya H et al.; for the AFTER Investigators. The Atrial Fibrillation in Turkey: Epidemiologic Registry (AFTER). Cardiol J, 2013; 20: 447-452.

5. Atarashi H, Inoue H, Okumura K, Yamashita T, Kumagai N, Origasa H; J-RHYTHM Registry Investigators. Present status of anticoagulation treatment in Japanese patients with atrial fibrillation: A report from the J-RHYTHM Registry. Circ J, 2011; 75: 1328-1333.

6. Shin HW, Kim YN, Bae HJ et al; KORAF Investigator. Trends in Oral Anticoagulation Therapy Among Korean Patients With Atrial Fibrillation: The KORean Atrial Fibrillation Investigation. Korean Circ J, 2012; 42: 113-117.

7. Waldo AL, Becker RC, Tapson VF, Colgan KJ; NABOR Steering Committee. Hospitalized patients with atrial fibrillation and a high risk of stroke are not being provided with adequate anticoagulation. J Am Coll Cardiol, 2005; 46: 1729-1736.

8. Nieuwlaat R, Capucci A, Camm AJ et al; European Heart Survey Investigators. Atrial fibrillation management: a prospective survey in ESC member countries: the Euro Heart Survey on Atrial Fibrillation. Eur Heart J, 2005; 26: 2422-2434.

9. Claes N, Van Laethem C, Goethals M et al. Prevalence of atrial fibrillation in adults participating in a large-scale voluntary screening programme in Belgium. Acta Cardiol, 2012; 67: 273-278.

10. Ertaş F, Kaya H, Atılgan ZA et al. Predictors of warfarin use in patients with non-valvular atrial fibrillation who presented to the cardiology outpatient clinic of a tertiary hospital in Turkey: An observational study. Turk J Med Sci, 2012; 42: 1172-1179.

11. Demirbağ R, Sade LE, Aydın M, Bozkurt A, Acartürk A. The Turkish registry of heart valve disease. Türk Kardiyol Dern Ars, 2013; 41: 1-10.

12. Ertaş F, Kaya H, Yüksel M, Soydinç MS, Alan S, Ülgen MS. Atrial Fibrillation in Turkey: Epidemiologic Registry (AFTER) Study Design. Anadolu Kardiyol Derg, 2013; 13: 339-343.

13. Whitlock RP, Sun JC, Fremes SE, Rubens FD, Teoh KH; American College of Chest Physicians. Antithrombotic and thrombolytic therapy for valvular disease: Antithrombotic Therapy and Prevention of Thrombosis. $9^{\text {th }}$ Ed.: American College of Chest Physicians Evidence-Based Clinical Practice Guidelines. Chest, 2012; 141: e576S-600S.

14. Pisters R, Lane DA, Nieuwlaat R, de Vos CB, Crijns HJ, Lip GY. A novel user-friendly score (HAS-BLED) to assess 1-year risk of major bleeding in patients with atrial fibrillation: the Euro Heart Survey. Chest, 2010; 138: 1093-1100.

15. Nabauer M, Gerth A, Limbourg T et al. The Registry of the German Competence NETwork on Atrial Fibrillation: patient characteristics and initial management. Europace, 2009; 11: 423-434.

16. Vahanian A, Alfieri O, Andreotti F et al.; Joint Task Force on the Management of Valvular Heart Disease of the European Society of Cardiology (ESC); European Association for Cardio-Thoracic Surgery (EACTS). Guidelines on the management of valvular heart disease (version 2012). Eur Heart J, 2012; 33: 2451-2496.

17. Gage BF, Waterman AD, Shannon W, Boechler M, Rich MW, Radford MJ. Validation of clinical classification schemes for predicting stroke: Results from the National Registry of Atrial Fibrillation. JAMA, 2001; 285: 2864-2870.

18. Lip GY, Nieuwlaat R, Pisters R, Lane DA, Crijns HJ. Refining clinical risk stratification for predicting stroke and thromboembolism in atrial fibrillation using a novel risk factor-based approach: The euro heart survey on atrial fibrillation. Chest, 2010; 137: 263-272. 